\title{
Big Data Analysis of e-Commerce Efficiency and Its Influencing Factors of Agricultural Products in China
}

\author{
Yi Wen, ${ }^{1}$ Lingxi Kong, ${ }^{1}$ and Gaoxiu Liu ${ }^{2}{ }^{2}$ \\ ${ }^{1}$ School of Energy and Environmental Sciences, Yunnan Normal University, Kunming 650500, China \\ ${ }^{2}$ School of Business and Tourism Management, Yunnan University, Kunming 650500, China \\ Correspondence should be addressed to Gaoxiu Liu; 34141630@qq.com
}

Received 2 August 2021; Revised 17 September 2021; Accepted 25 September 2021; Published 11 December 2021

Academic Editor: Sang-Bing Tsai

Copyright (C) 2021 Yi Wen et al. This is an open access article distributed under the Creative Commons Attribution License, which permits unrestricted use, distribution, and reproduction in any medium, provided the original work is properly cited.

At present, the e-commerce industry of agricultural products plays a pivotal role in promoting income growth and helping rural revitalization. This paper collected relevant data in the recent 8 years (2012 to 2019) and used the DEA model and Tobit model to analyze the correlation degree between the efficiency and various influencing factors in China. DEA analysis results show that, in recent years, three efficiencies are quite different: the comprehensive efficiency and scale efficiency show an upward trend, while the pure technical efficiency remains at a high level. Tobit model results show that the number of urban Internet users, rural Internet users, logistics practitioners, the development of national economy are negatively correlated with e-commerce efficiency; the length of traffic construction has no significant correlation; the level of agricultural mechanization has a significant positive correlation. Hence, the paper puts forward four suggestions.

\section{Introduction}

In recent ten years, Chinese rural e-commerce has evolved from the agricultural e-commerce stage to the rural e-commerce stage [1], and e-commerce has achieved remarkable results in helping targeted poverty alleviation [2]. In the future, e-commerce will play a vital role in promoting the increase of farmers' income; the integration of primary, secondary, and tertiary industries; and the return of talents for employment. The $14^{\text {th }}$ Five-Year Plan [3] indicates that the future will vigorously develop new forms of e-commerce, and the Ministry of Agriculture and Rural Affairs [4] also proposes that the online sales of agricultural products should reach 1 trillion yuan in 2025. As we can see, the e-commerce industry of agricultural products has a good development prospect.

Macro's research [5] on the efficiency and influencing factors of agricultural products e-commerce is rare, but the macro research is conducive to clearly showing the effectiveness of input and output in the process of e-commerce development and is conducive to the control of the future development and investment direction of agricultural products e-commerce. Therefore, this paper uses the DEA model and Tobit model to explore the efficiency and influencing factors of agricultural products e-commerce in the past eight years and puts forward suggestions for the future development of the agricultural products e-commerce industry.

\section{Literature Review}

Some scholars confused the difficulties of agricultural products e-commerce through qualitative analysis $[6,7]$ and put forward countermeasures. Rural e-commerce can help rural revitalization through policy path, infrastructure path, factor path, industry path, and extension path [8] and can also promote agricultural industry agglomeration [9]. In the future, it is necessary to improve the implementation of policies, improve infrastructure construction, introduce professional talents, comb through the awareness of agricultural products brand construction, and strive to overcome the practical obstacles such as unbalanced regional economic development and insufficient industrial integration. In quantitative analysis, scholars' research scope ranges 
from regional $[10,11]$ province $[12,13]$ to municipal [14-16] county [17, 18]. Wang [19] found that the development of rural e-commerce in China is ranked in the order of "eastern-central-northeast-western," but its influence on the regional economy is ranked in the order of "eastern-westerncentral-northeast," demonstrating that rural e-commerce has significant heterogeneity. Wang et al. [11] pointed out that the volume and quality of the agro-related e-commerce industry in eastern China are superior to those in western China, which further widens the gap in economic and social development levels. E-commerce of agricultural products in China is booming; however, there are some common problems in various regions and towns that need to be improved. For example, most rural e-commerce adoption is still at a digital disadvantage [20], the constructions of logistics infrastructure need to be improved [21], and rural e-commerce talents are in short supply [8].

Current research contents mainly cover poverty alleviation [22], digital credit [14], capital to the countryside [23], sustainable development of industry [24, 25], framework of rural e-commerce standardization system [26], college students' willingness to work in rural e-commerce [27], and so on. The content is rich in breadth and depth. Research subjects include agricultural products e-commerce service institutions [28-31], cross-border e-commerce enterprises $[32,33]$, and farmers [14].

One of the studies based on the empirical data of large rural professional households [34] found that demographic characteristics, family attributes, geographical conditions, policy perception, and technology perception have a significant impact on e-commerce technology adoption and investment decisions. Rural e-commerce clusters will stimulate the enthusiasm of rural families to start businesses and strengthen entrepreneurial behaviors [9]. Participation in e-commerce has a positive impact on both the digital credit scale and the total credit scale of farmers [14]. Rural cooperative organizations have certain advantages in terms of resources and channels [35] and have the potential to promote the development of agricultural products e-commerce; therefore, relevant government departments should strengthen supervision and guidance. These studies not only emphasize the importance of rural e-commerce but also provide the basis and path for digital financial transformation, the improvement of quality and efficiency of thirdparty service institutions, and the construction of the standardized system.

Scholars used Feder model [36], Tobit model [37], DEAMalmquist index method [12, 38], Heckman model [34], Lilien index [7], entropy method [19], factor analysis [20], and cluster analysis model [20] to explore the efficiency of cold chain logistics, enterprise operation efficiency, and poverty alleviation efficiency of e-commerce [39]. The field of agricultural products e-commerce fully reflects the interdisciplinary research method.

DEA is a nonparametric methodology based on linear programming to evaluate the relative efficiencies of a group of entities called decision-making units (DMUs). DMUs "must complete similar types of activities, produce similar types of products and service, consume similar types of resources, and perform under similar environmental constraints."

There are several characteristics of DEA that are relevant and appealing to this study. First of all, DEA can evaluate the efficiency of each decision-making unit by considering multiple output parameters at the same time. This overcomes a key limitation of other popular efficiency measures. Secondly, DEA does not assume the functional relationship between parameters or the distribution of efficiency scores. This is very important because it allows the analyst to consider key parameters such as the person's experience, often directly related to the learning curve, and is seen as nonlinear without the need to do data conversion. Thirdly, DEA evaluates the efficiency of a decision-making unit relative to other decision-making units. In this way, the DMU is always compared to the best performance, not to the average performance in the regression analysis. Fourthly, DEA is very suitable for the following situations: it is difficult to understand the differences in production practice of various decision-making units, and the importance level of parameters among them may be different. DEA assigns weights to the DMUS, displays a DMUS in its "best possible way," and then compares the efficiency of the DMUs under consideration. If the "best possible way" scenario results in another DMU being more efficient than the DMU in question, then there is strong evidence that the DMU is inefficient. Therefore, DEA can focus on finding evidence of the efficiency of a DMU relative to a group of DMU.

\section{Methodology and Data}

3.1. Research Design. In this paper, we combine the DEA and Tobit regressing model to appraise the e-commerce efficiency in China. In the first stage, the indicators of e-commerce efficiency are defined. And then, three groups of factors are selected to construct investment indicators, namely, information technology investment, logistics service investment, and infrastructure investment. The relative e-commerce efficiency is then assessed by the DEA model. Finally, we use the Tobit regression model to examine the effect of inputs on the e-commerce efficiency score calculated.

The research basis of the DEA method is relative efficiency. The advantage of this method is that the information and characteristics contained in the evaluation object are fully considered before the effective evaluation of the decision-making unit [40, 41], and there is no need for dimensionless transformation processing. CCR model [42] and BCC model [43] are commonly used in DEA methods. BCC model can effectively measure the technical effectiveness of decision-making units. It is assumed that there are $n$ decision-making units, and each decision-making unit $\mathrm{DMU}_{K}(k=1,2, \ldots, n)$ has $m$ inputs and $s$ outputs. This paper builds the following model: 


$$
\left(D_{\mathrm{BCC}}\right)\left\{\begin{array}{l}
\min \theta=V_{D_{1}}, \\
\text { s.t. } \\
\sum_{k=1}^{n} X_{k} \lambda_{k}+s^{-}=\theta X_{t}, \\
\sum_{k=1}^{n} X_{k} \lambda_{k}-s^{+}=Y_{t}, \\
\sum_{k=1}^{n} \lambda_{k}=1 \\
\lambda_{k} \geq 0, k=1,2, \ldots, n, \\
s^{+} \geq 0, s^{-} \geq 0 .
\end{array}\right.
$$

As China accelerates the construction of "Digital China" [44-46], rural e-commerce will develop rapidly, drive the increase of farmers' income [47], and promote the transformation and upgrading of agriculture. Therefore, the study of what factors affect the efficiency of agricultural products logistics and the degree of influence will be conducive to taking more effective targeted measures to promote the development of agricultural products e-commerce. Therefore, this paper uses Eviews as the Tobit regression model for analysis.

Since the e-commerce efficiency is discrete between 0 and 1 , it is limited as a dependent variable. To avoid parameter deviation [48], the regression method in this paper abandons the ordinary least square method and adopts the maximum likelihood method. The Tobit model constructed in this paper is as follows:

$$
Y=C+\beta_{1} X_{1}+\beta_{2} X_{2}+\beta_{3} X_{3}+\beta_{4} X_{4}+\beta_{5} X_{5}+\beta_{6} X_{6}+\varepsilon,
$$

where $Y$ represents the e-commerce efficiency of agricultural products in the past years. $X_{1}$ represents the number of urban Internet broadband users, and $X_{2}$ represents the number of rural Internet broadband users; these two items are used to measure the informatization level of urban and rural areas. $X_{3}$ represents the number of employees in the transportation industry, and $X_{4}$ represents the length of expressways and other transportation construction; these two items are used to measure the development level of logistics, an indispensable part of e-commerce. $X_{5}$ represents the national per capita disposable income of residents, which is used to measure China's economic development level and residents' consumption level. $X_{6}$ represents the total power of agricultural machinery, which is used to measure the level of agricultural mechanization. $C$ is the constant term and $\varepsilon$ is the random error term.

3.2. Data and Variables. From 2012 to 2019, there are 8 decision-making units for agricultural products e-commerce in China. The efficiency and economies of scale of agricultural products e-commerce are obtained by using DEP software, and the development status in recent years is analyzed.
Table 1 is the evaluation index system established in this paper. Three input indexes and one output index were selected in this paper. Input index data comes from the China Statistical Yearbook over the years, and output index data comes from the China E-Commerce Report released by the Department of E-Commerce. Among them, infrastructure investment $X_{3}$ is the data of railway operating mileage, highway mileage, domestic waterway mileage, and domestic and foreign flight route mileage. Since the data statistics in the 2020 Yearbook are from the end of 2019, the data span in this paper is from 2012 to 2019.

\section{Results and Discussion}

4.1. Static Analysis Based on the DEA Model. The condition of the DEA model is $n \geq 2(m+s)$, so the selection of data and indicators in this paper meets the measurement standard of the DEA model.

The results are shown in Table 2. According to the average results over the years, the three efficiencies differ greatly, and the comprehensive efficiency is just over $50 \%$, that is, the average electronic efficiency of agricultural products is low. From the overall trend, from 2012 to 2019, the comprehensive efficiency and scale efficiency show an upward trend, while the pure technical efficiency remains at a high level. That is to say, China's agricultural products e-commerce develops vigorously and will maintain a highefficiency level in the future.

From the perspective of scale efficiency, with the development of the national economy and the increasing emphasis on agriculture, the scope and scale of China's investment in infrastructure, logistics services, and information technology promotion are increasing day by day, and the scale efficiency has increased significantly. There was a slight decline in 2018, which may be due to the emergence of B2B trading platforms for agricultural products in China, represented by Pinduoduo, Webku, Meicai, and so on. The emergence of this model promoted the scale of producing areas and enhanced the market competitiveness of products and agricultural enterprises. Therefore, marginal efficiency was generated with the increase of input, but the input and output reached the "optimal state" in 2019.

From the perspective of pure technical efficiency, the efficiency over the years is above $99 \%$, and the overall remarkable effect has been achieved. China has high management and technical efficiency in agricultural products e-commerce; that is, China has a high utilization rate of the input resources.

From the perspective of comprehensive efficiency, China's agricultural products e-commerce at the early stage has problems such as miscellany of input and output and extremely low efficiency. With the gradual improvement of agricultural products e-commerce logistics, service and professional personnel training systems of county-level operation, and the popularization of rural information services, the efficiency of agricultural products e-commerce has increased and maintained a state of high efficiency. In 2016, the number of e-commerce comprehensive demonstration projects in rural areas surged, and the coverage of 
TABLE 1: Evaluation index system of e-commerce efficiency of agricultural products.

\begin{tabular}{lcc}
\hline Index type & Level indicators & Secondary indicators \\
\hline $\begin{array}{l}\text { Output } \\
\text { indicators }\end{array}$ & $\begin{array}{c}\text { The development level of agricultural } \\
\text { products e-commerce } \\
\text { Information technology investment }\end{array}$ & $\begin{array}{c}\text { Online retail sales of agricultural products, } Y \\
\text { Number of internet broadband subscribers, } X_{1}\end{array}$ \\
\hline $\begin{array}{l}\text { Input } \\
\text { indicators }\end{array}$ & $\begin{array}{c}\text { Logistics service input } \\
\text { Infrastructure investment }\end{array}$ & $\begin{array}{c}\text { Total number of employees in communications, transportation, postal } \\
\text { services, and primary industries, } X_{2}\end{array}$ \\
\hline
\end{tabular}

TABLe 2: The DEA empirical results of agricultural e-commerce efficiency from 2012 to 2019.

\begin{tabular}{lcccc}
\hline Firm & Crste & Vrste & Scale & Scale reward \\
\hline 2012 & 0.030 & 1 & 0.030 & Irs \\
2013 & 0.112 & 0.996 & 0.112 & Irs \\
2014 & 0.237 & 1 & 0.237 & Irs \\
2015 & 0.356 & 1 & 0.356 & Irs \\
2016 & 0.791 & 1 & 0.791 & Irs \\
2017 & 0.940 & 1 & 0.940 & Irs \\
2018 & 0.908 & 0.999 & 0.910 & Irs \\
2019 & 1 & 1 & 1 & - \\
Mean & 0.547 & 0.999 & 0.547 & \\
\hline
\end{tabular}

county-level operation centers and rural service stations was further expanded $[49,50]$. In those years, the Ministry of Commerce also supported 15 provinces to build local cold chain centers for agricultural products storage [51]. Since that year, the construction of the rural market system has been gradually improved, and the development of e-commerce has been characterized by regional characteristics, diversified market entities, and diversified modes.

4.2. Static Analysis Based on the Tobit Model. Table 3 reports the Tobit regression results for scale efficiency, and the empirical results differ greatly from the author's hypothesis and expectation. The reasons are analyzed below.

$X_{1}$ represents the number of urban Internet broadband users, and the index coefficient is negative $(P<0.001)$; that is, the number of urban Internet users is significantly correlated with the efficiency of e-commerce in China. The results show the popularity of a highly significant correlation. $X_{2}$ represents the number of rural Internet broadband users, and the index coefficient is negative $(P<0.05)$; that is, the number of rural Internet users is significantly correlated with the efficiency of e-commerce in China. The results show that the popularity of information networks is related to the efficiency of agricultural products e-commerce, and the influence is significant. The urban informatization degree has a more significant impact on agricultural products e-commerce than the rural informatization degree. The electricity generation and sales mode of agricultural products is as follows: agricultural products are purchased by consumers, especially urban consumer groups, through online sales from front-end markets such as rural areas, agricultural product industrial parks, and agricultural product trading markets, and then delivered to consumer markets through offline logistics. Therefore, in the early stage of the development of online sales of agricultural products, the circulation direction of products is more from rural areas to towns, so the development of urban information network has a more significant impact.. And agricultural enterprises are responsible for collecting the produce of the farmers to resellers or agricultural industrial park in bulk sales of agricultural products e-commerce mode and make the farmers themselves less directly involved in agricultural e-commerce sales system, so the Internet popularization level impact on the efficiency of agricultural e-commerce compared to towns have a significant impact on the efficiency of the Internet.

$X_{3}$ represents the number of employees in the transportation, postal, and transportation industries. The index coefficient is negative $(P<0.001)$; that is, the number of logistics employees is significantly and negatively correlated with the efficiency of e-commerce in China. On the one hand, although the human capital investment in the logistics service industry increases sharply, there are fewer leading enterprises in agricultural products logistics and fewer persons serving in agricultural products logistics. Therefore, the more the logistics practitioners are, the lower the proportion of the agricultural products logistics personnel may be, so there is a negative correlation. On the other hand, the professional quality level of logistics personnel needs to be improved. Due to the late opening of logistics major in China and the lack of courses focusing on agricultural product logistics, there is a shortage of professionals in agricultural product logistics technology and management, which effectively inhibits the resource allocation and negative correlation of agricultural product e-commerce.

$X_{4}$ represents the length of the expressway and other traffic construction $(P>0.05)$; that is, the length of traffic construction is not significantly correlated with the efficiency of e-commerce in China. There are two explanations for this phenomenon in this paper. Firstly, to promote the rapid development of the regional economy in recent years, road, railway, water transport, 
TABLE 3: Results of the Tobit model on the influencing factors of agricultural e-commerce efficiency.

\begin{tabular}{lccr}
\hline Variable & Coef. & Std. err. & Prob value \\
\hline$Y$ & - & - & - \\
$X_{1}$ & -0.0000312 & $2.62 e-07$ & $<0.001$ \\
$X_{2}$ & $-6.19 e-06$ & $7.16 e-07$ & $<0.050$ \\
$X_{3}$ & -0.0002858 & $2.91 e-06$ & $<0.001$ \\
$X_{4}$ & -0.000037 & 0.0000142 & $>0.050$ \\
$X_{5}$ & -0.0000164 & $4.05 e-07$ & $<0.010$ \\
$X_{6}$ & 0.0000207 & $4.37 e-08$ & $<0.001$ \\
$C$ & -0.2396994 & 0.007969 & $<0.010$ \\
\hline
\end{tabular}

air transportation, and other transportation constructions are in full force, and the length of new transportation lines is large. Under this national condition, the quantity change has not changed the efficiency improvement of agricultural products e-commerce temporarily. Secondly, there may be a blind investment in highway construction in China, and repeated construction may lead to a low utilization rate of investment. Third, part of the transportation route or the current situation of the quality and level is not enough. The relatively poor transportation conditions lead to transport time extension of agricultural products, increase in the damage rate of agricultural products in the transport process, thus hindering the improvement of the logistics efficiency. For example, the shortage of cold chain logistics makes the fresh agricultural products circulation loss rate 8 times that of the developed countries.

$X_{5}$ represents the per capita disposable income of national residents, and the index coefficient is negative $(P<0.01)$; that is, the development of the national economy at a significant level of $1 \%$ has a significant negative correlation with the impact on China's e-commerce efficiency. The national per capita disposable income of residents reflects the development level of China's national economy. With the development of the national economy, the choice of e-commerce products for Chinese residents is becoming increasingly rich, and the online sales volume is increasing year by year. Although the online sales volume of agricultural products is also increasing, its proportion is not obvious. Moreover, the online sales volume of agricultural products accounts for $3 \%$ of the sales volume of agricultural products. The development potential and space of agricultural products e-commerce are huge, and the influence of the national economy lags, which has not yet been reflected in the field of agricultural products e-commerce.

$X_{6}$ represents the total power of agricultural machinery, $P<0.001$, and the coefficient is positive; that is, the level of agricultural modernization and mechanization has a very significant positive correlation with China's e-commerce efficiency. Raising the level of agricultural mechanization improved the agricultural output and quality improved, the scale of agricultural production and processing, and the market share of agricultural product sales but also reduced the agricultural products from production to processing and circulation loss and improved the speed of the batch transportation of agricultural products and sales. Therefore, the improvement of agricultural mechanization level improves the efficiency of agricultural e-commerce.

\section{Policy Implications}

Based on the significant positive correlation between the level of agricultural mechanization and e-commerce efficiency, agricultural products e-commerce should focus on strengthening modern agricultural science and technology and the research and development of agricultural machinery and tools and spread the use of the original agricultural land to modernize. We should improve the integration of agricultural machinery and agronomy and the organization cultivation of socialized service of agricultural machinery and strive to build a new business model of "whole-process mechanization + comprehensive agricultural service." We should also improve the level of independent research and development of agricultural machinery and equipment, according to the different topography, climate conditions, and crop characteristics to prepare intelligent agricultural machinery and tools; play the role of science and technology commissioners and improve the utilization rate of agricultural machinery. We will increase subsidies and encourage farmers and agricultural enterprises become mechanized production mode.

Based on the result that the length of expressway construction is not significantly correlated with the efficiency of e-commerce, the government needs to reflect and pay attention to rural road construction. While actively building high-speed railways and expressways, we also pay attention to rural roads, building and maintaining hardening roads and main roads within villages, and increasing direct roads between natural administrative villages and surrounding villages and county seats. At the same time, we should strengthen the cold chain transport mode of upstream and downstream connection and low-temperature distribution. We should increase the quantity of cold storage of agricultural products along the routes, to reduce the loss of agricultural products e-commerce transportation.

Based on the results that the degree of urban informatization has a more significant impact on agricultural products e-commerce, agricultural subjects such as rural e-commerce related enterprises, cooperatives, and large farmers should promote the green development of agriculture in the future and strengthen the quality inspection of agricultural products and the supervision of online agricultural products and food safety. Given the current situation of rich categories, large quantities, and serious homogenization of e-commerce products, China's 
agricultural products should pay attention to the advantages and values of local characteristic agricultural products and brand construction of agricultural products and improve brand awareness. The development of "green organic produce" and "geographical indication produce" should be encouraged. We will extend the processing chain of agricultural products and increase the added value of agricultural products.

Based on the negative correlation between the current logistics practitioners and the efficiency of agricultural products e-commerce, future logistics enterprises should improve the professional quality of logistics practitioners and strengthen the training of their information application ability, management ability, and other skills, to improve the quality and efficiency of logistics service. Colleges and universities and vocational and technical schools in all provinces and cities should pay attention to agricultural products logistics, set up corresponding majors, carry out corresponding courses, differentiate training programs of ordinary logistics express, and develop targeted training models of agricultural products e-commerce logistics, to establish a correct outlook on career and employment, cultivate young people's sense of identity with their hometown, and attract relevant professionals to return to their hometown and agriculture for employment.

\section{Conclusions}

Due to the data from the National Bureau of Statistics of China, this paper presents a DEA model consisting of 3 inputs and 1 output to measure the efficiency of e-commerce of agricultural products in China. The contributions of this research are that we have proposed a "broader picture" of the efficiency of e-commerce of agricultural products. The results of our study found some interesting phenomena. The number of logistics employees is significantly and negatively correlated with the efficiency of e-commerce in China, and it is speculated that the reason may be that the human capital input of the logistics service industry has increased significantly, but the personnel serving agricultural products logistics are less and the professional quality level of logistics personnel is low. The length of traffic construction is not significantly correlated with the efficiency of e-commerce; it may be because there are many new roads and railways, but the new routes are not the logistics transportation routes of agricultural products, and the relatively bad transportation conditions lead to the extension of transportation time which is proportional to the damage rate of agricultural products in the transportation process.

Although this study provides meaningful implications for the efficiency of e-commerce evaluation, it has some limitations and thus has further research issues. On the one hand, more representative indicators can be analyzed in future studies, and the results may be more accurate. More diversified indicators can be paid attention to, for example, the influence of policy guidance of agricultural products of all provinces and cities nationwide, funds for agricultural e-commerce assistance, and other factors on the efficiency of agricultural e-commerce. On the other hand, a dynamic approach, such as the Malmquist approach, can also be adopted.

\section{Data Availability}

The data required to reproduce these findings can not be shared at this time as the data also form part of an ongoing study.

\section{Conflicts of Interest}

The authors declare that they have no conflicts of interest.

\section{References}

[1] J. Liu and W. Shen, "Study on the evolution process and path of rural e-commerce," Commercial Economics Research, vol. 19, pp. 123-126, 2019.

[2] D. Yuan and J. Peng, "The development path of rural E-commerce based on targeted poverty alleviation: a case study in Guangdong province," International Journal of Computational and Engineering, vol. 6, no. 1, 2021.

[3] H. Wei, "Ten new directions for China's agricultural and rural development during the 14th five-year plan period," China Economic Times, vol. 3, 2020.

[4] Ministry of Agriculture and Rural Affairs "Promoting comprehensive rural revitalization through industrial development: the ministry of agriculture and rural affairs issued the national development plan for rural industries (2020-2025)," Agricultural Economy, vol. 8, pp. 11-13, 2020.

[5] M. Li, Q. Zhang, and S. Gao, "The spatial aggregation of rural e-commerce in China: an empirical investigation into Taobao villages," Journal of Rural Studies, vol. 80, pp. 403-417, 2020.

[6] X. Wang and Q. Zhang, "The internal mechanism of E-commerce to solve the dilemma of fresh agricultural products circulation: based on the double case comparative study of tmall fresh products and tuotuo workers society," China Soft Science, vol. 2, pp. 39-55, 2016.

[7] S. Wang and Z. Ding, "Ecosystem of E-commerce of agricultural products: a theoretical analysis framework," China Rural Watch, vol. 4, pp. 39-48, 2015.

[8] L. Xu and Y. Zheng, "Path analysis of rural e-commerce to help rural revitalization," Journal of Graduate School of Chinese Academy of Social Sciences, vol. 2, pp. 109-120, 2021.

[9] R. Yu, "Study on the influence mechanism of rural e-commerce industrial cluster on rural family entrepreneurship," Commercial Economics Research, vol. 10, pp. 128-131, 2021.

[10] R. Du, S. Yu, and J. Qu, "Input-output efficiency and influencing factors of agricultural products e-commerce in China: based on regional perspective," Contemporary Economic, vol. 1, pp. 77-81, 2021.

[11] H. Wang, X. Chen, and Y. Yang, "Study on the difference between east and west of agricultural products e-commerce development," Statistics \& Decisions, vol. 36, no. 2, pp. 93-96, 2020.

[12] D. Zheng, Study on Logistics Efficiency of Agricultural Products in Yunnan Province, Yunnan Normal University, Kunming, China, 2018.

[13] Q. Li and Y. Deng, "Research on the path of improving the service quality of rural E-commerce logistics in Jilin province based on computer," Journal of Physics: Conference Series, vol. 1744 , no. $3,2021$.

[14] J. Liu, C. Li, and S. Han, "Rural e-commerce development and farmers' digital credit behavior: microscopic evidence from 
Jiangsu “Taobao village"," Chinese Rural Economy, vol. 11, pp. 97-112, 2020.

[15] M. Chen and Y. Zou, "The impact of E-commerce on the development of rural areas in the context of rural revitalization: a case study of Beihai city, Guangxi province," Shanghai Business, vol. 5, pp. 32-33, 2021.

[16] X. Leng, "Analysis on the development environment of characteristic agricultural products e-commerce in Xinxiang," Enterprise Technology and Development, vol. 2, pp. 151-152, 2021.

[17] Y. Lin, Y. Liu, and Z. Lin, "Investigation and research on the current situation of rural e-commerce under the new era of comprehensive poverty alleviation: a case study of Hongxing village, Yonghan town, Longmen county, Huizhou city," Modern Marketing, vol. 6, pp. 163-164, 2021.

[18] C. Huang, B. Guo, and J. Guo, "Research report on factors restricting the development of E-commerce of agricultural products in west Guangdong: a case study of Pingfeng town, Fengkai county, Zhaoqing city," Rural Economy and Science Technology, vol. 32, no. 1, pp. 125-128, 2021.

[19] Q. Wang, "Research on the relationship between rural E-commerce and regional economy coordinated development in China," Commercial Economics Research, vol. 23, pp. 129-132, 2020.

[20] J. Wan, G. Chen, and Y. Liu, "Influencing factors and development strategies of provincial rural e-commerce performance in China," Commercial Economics Research, vol. 6, pp. 75-78, 2021.

[21] H. Feng, "Research on the development mode and promotion path of rural e-commerce," Agricultural Economy, vol. 4, pp. 137-138, 2021.

[22] X. Yang and H. Shi, "Spatial characteristics and influencing factors of poverty alleviation efficiency of E-commerce: a case study of dabie mountains," Statistics \& Decisions, vol. 35, no. 16, pp. 103-107, 2019.

[23] L. Zhou, "Another kind of "capital to the countryside": the process and mechanism of e-commerce capital embedded in rural society," China's Rural Economy, vol. 12, pp. 35-55, 2020.

[24] N. Li, "Efficiency evaluation of sustainable development of cross-border e-commerce industry in China: based on threestage DEA model," Science and Technology and Economics, vol. 33, no. 1, pp. 106-110, 2020.

[25] R. Li, "Research on the sustainable development of rural E-commerce tourism based on the big data analysis from the perspective of urban and rural development balance," Journal of Physics: Conference Series, vol. 1744, no. 3, 2021.

[26] J. Wu, "The present situation and development system framework of rural e-commerce standardization in China," Commercial Economics Research, vol. 23, pp. 136-139, 2020.

[27] L. Gao and X. Zhang, "Analysis on the influence factors of college students about the willingness to work in rural e-commerce," Applied Mathematics and Nonlinear Sciences, vol. 6, no. 1, 2021.

[28] G. Pan, Efficiency Evaluation and Influencing Factors of $\mathrm{O} 2 \mathrm{O}$ E-Commerce Website Based on DEA Method, South China University of Technology, Guangzhou, China, 2016.

[29] W. Xu, Research on Collaborative Efficiency and Cost Saving Value Allocation of Collaborative Distribution Mode in E-Commerce Environment, Southwest Jiaotong University, Chengdu, China, 2016.

[30] S. He, Study on the Spatial Distribution and Market Influencing Factors of Agricultural Cold Chain Logistics Enterprises,
Shanghai University of Finance and Economics, Shanghai, China, 2020.

[31] X. Yang, "Analysis on the role of service providers in promoting the development of rural E-commerce: take luoyang shanxun company as an example," International Journal of Economics, Finance and Management Sciences, vol. 9, no. 3, 2021.

[32] S. Xu and H. Ye, "Evaluation of operating efficiency of listed cross-border E-commerce enterprises: based on three-stage DEA model," Technological Economics and Management Research, vol. 10, pp. 75-81, 2019.

[33] M. Li, Research on Logistics Efficiency of Small and MediumSized Cross-Border E-Commerce Enterprises and its Influencing Factors, Anhui University of Finance, Bengbu, China, 2018.

[34] X. Wang, "Technology adoption and investment decision of large rural professional E-commerce: an empirical study based on heckman model," Journal of Xi'an University of Finance and Economics, vol. 3, no. 34, pp. 69-80, 2021.

[35] J. Zhou, "Research on the optimization of agricultural products network marketing mode based on rural cooperative organization," Agricultural Economy, vol. 9, pp. 139-140, 2018.

[36] J. Zhang and H. Tang, "Effect decomposition and spatial diffusion of poverty alleviation efficiency of E-commerce: spatial dupin analysis based on modified feder model," Journal of Social Science of Hunan Normal University, vol. 48, no. 5, pp. 87-96, 2019.

[37] G. Tian, M. Zhang, and Z. Li, "Analysis on the technical efficiency of fresh agricultural products e-commerce enterprises and its influencing factors: based on improved DEA method and tobit model," Journal of Hunan Agricultural University, Social Science Edition, vol. 19, no. 5, pp. 80-87, 2018.

[38] D. Shen and Y. Yang, "Research on the impact of agricultural products e-commerce industrial agglomeration on industrial total factor productivity in Jilin province-based on the data of Alibaba platform," Mathematical Statistics and Management, vol. 39, no. 3, pp. 385-396, 2020.

[39] Y. Zhang, R. Deng, and J. Chen, "Analysis on development efficiency of rural E-commerce based on DEA in Sichuan province," E3S Web of Conferences, vol. 253, p. 01061, 2021.

[40] W. Su, Study on the Theory and Method of Multi-Index Comprehensive Evaluation, Xiamen University, Xiamen, China, 2020.

[41] K. Chen, X. Ren, and G. Yang, "A novel approach for assessing academic journals: application of integer DEA model for management science and operations research field," Inform, vol. 15, no. 3, 2021.

[42] L. Ma, DEA Theory and Application Research, Shandong University, Jinan, China, 2017.

[43] M. Li and G. Chen, "Research and application of data envelopment analysis method," Engineering Science China, vol. 6, pp. 88-94, 2003.

[44] E. Jin, Research on Innovation of Agricultural Products Circulation System under Digital Rural Strategy, Nanchang University, Nanchang, China, 2020.

[45] H. Zhang, K. Du, and B. Jin, "Research on evaluation of digital rural development readiness under rural revitalization strategy," Journal of Xi'an University of Finance and Economics, vol. 33, no. 1, pp. 51-60, 2020.

[46] S. Liu, "Targeting path and policy supply of high quality development of China's digital economy," Economist, De, vol. 6, pp. 52-61, 2019. 
[47] G. Lin, Research on the Mechanism of Rural E-Commerce Poverty Alleviation and Promotion Mechanism of Poverty Alleviation, Graduate School of Chinese Academy of Social Sciences, Beijing, China, 2016.

[48] H. Zhou and X. Li, "Estimation method and application of tobit model," Economics Information, vol. 5, pp. 105-119, 2012.

[49] Y. Ceng, H. Yang, and H. Guo, "Top design of rural informatization development: policy review and prospect," Journal of Agricultural and Forestry Economics and Management, vol. 19, no. 1, pp. 67-76, 2020.

[50] P. Wang, Research on the Strategy of Rural E-Commerce Promoting Precision Poverty Alleviation: A Case Study of Luquan Lecuntao Company, Yunnan University of Finance and Economics, Kunming, China, 2019.

[51] Y. Xi, "Constructing modern logistics system: provide strong support and guarantee for economic and social development," China Logistics and Purchasing, vol. 6, pp. 42-48, 2018. 